\title{
Teaching Pronunciation: The Lost Ring of the Chain
}

\author{
Majid Soltani Moghaddam \\ University of Tehran, Tehran, Iran \\ Email: mjd.slm@gmail.com \\ Morteza Nasiri \\ University of Tehran, Tehran, Iran \\ Email: mortezanasiri85@yahoo.com \\ Alireza Zarea \\ University of Tehran, Tehran, Iran \\ Email: alireza_zarea@hotmail.com \\ Sajjad Sepehrinia \\ University of Tehran, Tehran, Iran \\ Email: ssepehrinia@yahoo.com
}

\begin{abstract}
Recent developments in the literature provide us with a better understanding of the importance of second language pronunciation teaching which has been intermittently downplayed for years. This study aims at describing and understanding the different approaches to teaching pronunciation. It first gives an account of different views on pronunciation and its teachability. Then segmental and suprasegmental features and their place in language teaching programs are brought to notice. Since achieving settlement in whether teachers should set native-like accent or a fluent but accented style of speaking as the target in the pronunciation teaching programs has remained a thorny issue, a discussion of the related lines of arguments is presented. Finally, the future directions and consequent problems are discussed in the light of findings.
\end{abstract}

Index Terms - teaching pronunciation, teachability, segmental and suprasegmental features, accent

\section{INTRODUCTION}

Pronunciation teaching has not always been popular with teachers and theorists. However, for communicating effectively, learners need to become proficient in using the phonological elements of the language being learned. This need is tow-fold: learners' pronunciation is responsible for intelligibility, plus, pronunciation plays a central role in the way learners identify their membership in a special community. Pronunciation is the language feature which easily distinguishes native speakers from non-native speakers of languages in general and English in particular. Although pronunciation teaching has placed its much emphasis on the articulation of consonants and vowels in the past, the emphasis has recently shifted to a more comprehensive scope to include suprasegmental features.

\section{BACKGROUND}

It seems that teaching pronunciation gained momentum with the advent of Reform Movement in the 1880s. That was when the scientific analysis and description of the sound systems of languages were established. Furthermore, the main focus shifted from written to spoken mode; hence the International Phonetic Association was founded in 1886 (Richards and Rodgers, 2001). This attention to spoken language gave rise to phonetic training in order to establish good pronunciation habits. On the other hand, material developers also began to write instructional books for teaching pronunciation.

Different methods have considered the role of pronunciation from different viewpoints. Grammar- Translation method and Audiolingual method in the United States (Situational Language Teaching in Britain) can be located on the two extremes of a cline. Grammar-Translation method virtually gave no importance to pronunciation while in Audiolingualism it was a matter of maximum concern in a way that most of its typical activities i.e., minimal pairs, and short conversations were centered upon pronunciation. Some of these approaches to language teaching have pushed teaching pronunciation aside altogether adducing reasons that teaching pronunciation has little (if any) effect on learners pronunciation.

By and large, teaching pronunciation has undergone a move from sound manipulation exercises to communication activities, and also from a focus on isolated forms to the functioning of pronunciation in discourse. As Jones (2002) 
argues, with the development of recording technology and rise of Audiolingualism, such methods (listen and repeat) became the stock-in-trade of language teaching, and although now widely discredited in the areas of grammar and vocabulary teaching this approach has persisted in the teaching of pronunciation.

However, communicative approaches set their goals according to inherent notions of their approach that is communication of meaning which in its own turn involves teaching pronunciation. To them what counts is negotiating successfully. When the learner understands and is understood in the context, it is believed that his or her use of phonological patterns of the language in the question has been appropriate. Nonetheless, although both imitation and dissemination drills have an important role in the teaching of pronunciation as a means to help articulation become more automatic, they can be seen as a step toward more meaningful and communicative practice.

Acton (1984) argues that drills can also be made more lively and memorable by concentrating not just on oral and aural modalities, but also including visual representations and training in the awareness of kinesthetic sensation. He continues that a host of material writers have begun to recognize the importance of other modalities in pronunciation training, combining pictures, gestures and social activities with drills, along the lines off total physical response.

Task-based instruction offers pronunciation teaching a considerable scope for development in many respects (Ellis, 2003). Learners' attention can be drawn to the intonation and rhythm of sentences produced during the task. In the focus on form task, learners have more chances to practice and bring some modifications to their mispronunciations. On the other hand, when much focus is on the negotiation of meaning not on the form; they are involved in a reciprocal process of language in which unconsciously their pronunciation will be enhanced. However, task-based instructions' full potential has yet to be explored. As for learning goals, these are not that crystal clear.

Another consideration which cannot be overlooked by any means is that in the area of ELT profession many users of English need the language for lingua franca communication with other "non-native" speakers as well as with native speaker (Widdowson, 1990). The implications of the research in this area will take a while to influence the formulation of learning priorities and targets (Seidlhofern \& Dalton-Puffer, 1995). As a result, nobody can question the idea that the measure for successful pronunciation should be the speaker's degree of intelligibility as determined by a native-speaker. Since the majority of English speakers around the world are non-native speakers of English, it is quite reasonable to expect that more exchanges occur between non-native speakers of English than between non-native speakers and native-speakers.

\section{A. Teachability of Pronunciation}

The proponents of the idea that direct teaching of pronunciation is impossible center their rationale on two suppositions at which a barrage of criticisms have been leveled. It seems that the lack of success in teaching pronunciation in the literature, in comparison to other areas of language teaching e.g. vocabulary, grammar, etc. has led this group of scholars to construe this disappointment as inteachability of pronunciation. When Lenneberg (1967) introduced the well-known hypothesis of critical period, it came to every researcher as a breakthrough. In fact, it was a breakthrough in the sense that it drew every body's attention to the significance of age in learning a language and also all its subclasses of skills. Nevertheless, Lenneberg played fast and loose with his definitions. Because as Flege (as cited in Jones, 2002) points out the hypothesis itself is difficult to test, for it is hard to isolate speech learning from other factors associated with age.

The opponents of teaching pronunciation have taken Critical Period Hypothesis as their point of departure (Goodwin, 2001). There are a lot of studies which share the conclusion that children outperform adults when learning the pronunciation of a second language (e. g. Brown, 2007). However, they have not claimed that it is impossible for adults to acquire native-like pronunciation. It would be a bizarre claim that adults can make use of their L2 pronunciation in a way that some delicate adjustments in the oral cavity may help them approximate the L2 pronunciation. Children also can benefit from L1, but they seem to be in trouble when some consciousness-raising is involved. It is also possible that age-related differences be a result of various learning strategies among different age groups or even an offshoot of sociocultural variables. The implication of the above-mentioned research on the development of pronunciation teaching materials is not that adults should be denied training in pronunciation. Jones (2002) maintains that learners of different ages may respond differently, both emotionally and cognitively, to different kinds of teaching approaches and task types.

The second supposition which goes against teaching pronunciation is that there are some acquisition variables which have the major role in second language pronunciation. According to their argument these variables cannot be affected by explicit teaching of formal rules in classroom situations. This assumption was put forward by Krashen in 1982. Such a belief had a great effect on the course books of the 1970s that lack pronunciation parts in them was quite a common practice.

The advocates of this idea believed that teachers had no control over factors which were significant in actuation of the second language system i.e., aptitude, motivation, and interaction with native speakers. In their opinion, exposure to out-of-classroom situation language is both necessary and sufficient. The problem with this view is that, on the one hand, usually we have scant access to native speakers let alone second language environment, and on the other hand, this fact has been neglected that classrooms and teachers can be of much assistance in fostering motivation and exposure. Jones (2002) points out that pronunciation teaching methods should address the issues of motivation and exposure to native speaker input. 


\section{B. Segmental and Suprasegmental Features}

Roach (2000) classifies suprasegmental features of English as stress, pitch, rhythm, intonation, and juncture. English by its nature is affected by intonation to a great extent. For example, intonation functions as a signal of grammatical structure in English. This is most obvious in marking sentence, clause, and other boundaries. It also functions to clarify the contrasts between question types and the way in which questions differ from statements. Furthermore, intonation is used to express speakers' personal attitude or emotion along with other prosodic and paralinguistic features. Intonation has many other functions; it gives turn-taking clues in conversation and may also reveal social backgrounds of the speaker as well. Despite all these vital functions, it is not systematically taught.

Unfortunately, what teachers have at their disposal now is a handful of suggestions which lack authentic data to show the reliability of recommended approaches and procedures. Teachers should exercise care so that they do not adopt whatever they find in their immediate environment since this may lead to induced errors.

Generally, teachers have come to this conclusion that either meaning or segmental accuracy alone cannot be a safe criterion for teaching pronunciation. Goodwin (2001) best describes the situation, just as ESL teachers have acknowledged that an emphasis on meaning and communicative intent alone will not be enough to achieve grammatical accuracy. Pronunciation has emerged from the segmental/suprasegmental debate to a more balanced view which recognizes that a lack of intelligibility can be attributed to both micro and macro features. Therefore, the question is not whether to teach segmental or suprasegmental features, rather, what features to teach to learners in a way that they will be able to get their messages across and understand the incoming content.

\section{Point of Departure}

As a rule of thumb, learning in general and learning the sound system of a language in particular will improve if learners have a voice in decision making process. Although controlled by the ultimate authorities, learners' personal ideas and their likes and dislikes should be taken into account. Moreover, it has been proved that having some understanding of pedagogical assumptions behind the classroom activities on learner's part will help us achieve our main purposes more easily. The teacher should clarify the role of pronunciation to learners. It is their right, after all, to know the advantage of internalizing the second language sound system.

Hebert (2002) contends that by introducing learners to some of the prosodic features of English, learners can understand the reasons for activities used in the classroom. She adds that the aforementioned knowledge makes learners evaluate their own progress and provide them with strategies to use in communicative exchanges outside the classroom. In case of grown-ups this can be done much more easily because their background knowledge helps them understand the ambiguous concepts and ask questions when they are not sure about the appropriateness of their interpretations. Not surprisingly, a quite different approach is needed when it comes to children. The teacher should make use of simplified speech, clarification gestures, and graphic representations to help young learners understand the phonological twists and turns.

\section{Setting Realistic Goals: Native-like Accent or Acccented Fluency?}

According to Hebert (2002), spoken language imparts referential and affective meaning. When we speak we reveal our interest and attitudes toward the topic being discussed and toward the people we are speaking with. These messages are largely conveyed through the prosodic features of language, namely stress, rhythm, intonation, pitch variation, and volume. For these reasons, it would seem essential that phonology be learned in context and not treated incidentally and/or separately. However, this question remains to be addressed: which one should be set as the target in the learning of pronunciation, native-like accent or a fluent but accented style of speaking?

Morley (1994) has introduced four main goals for teaching pronunciation: functional intelligibility, functional communicability, increased self-confidence, and speech monitoring abilities. Accent may impede intelligibility. On the other hand, as Goodwin argues, "learners rarely achieve an accent-free pronunciation" (2001). It seems that since the reduction of $\mathrm{L} 1$ accent is almost impossible, we have to accept that provided that accent is not distracting to the native listener, trying to get rid of L1 accent would be so irrelevant. Instead of reducing L1 accent, adding a new accent should be the goal for learners to achieve. Having practiced the phonological patterns of the second language, learners can be hopeful to get achieve fluency in L2 pronunciation despite their L1 accent. This practice has a focus on meaningful chunks rather than isolated words and in order to integrate pronunciation effectively into other language activities, priority should be given to factors that contribute more significantly to an intelligible communication.

What Brown (2007) calls "Henry Kissinger effect" in honor of the U.S. secretary of state is a tangible example of bad pronunciation and very eloquent and intelligible speech which clearly exceeded that of many American native-speakers. Even a noticeable accent should not embarrass learners who are grappling to communicate effectively. In addition, authorities are likely to emphasize and pay more attention to learner' sociolinguistic conditions. They will be more inclined to make an attempt to find ways of dealing with the psychological aspects of pronunciation training, integrating confidence-building and reflective activities into their courses.

On the other hand, if the emphasis is put on fluency rather than accuracy of pronunciation, learners would not receive feedback on their pronunciation being interrupted while speaking and would feel more emotionally willing to express their opinion. Immediate feedback or interrupting learners in the middle of interactional activities has been found to be 
disruptive and demotivating and likely to distract learners and divert their attention away from meaning. In other words, it is likely to detract from the learning of automaticity and the associated strategies of learning (Clariana et al., 2000).

In fact, setting native-like accent as the ultimate goal in teaching pronunciation would be not only far-reaching but also unrealistic. It is really paradoxical to reduce one accent on the one hand, and to add another on the other hand while, linguistically speaking, no language has priority over the other. Therefore, while maintaining the home accent, learners should make an attempt to achieve functional communicability and fluency in order for a successful performance in different contexts the learner will face. Setting too high standards for achieving native-like accent can have detrimental corollaries despite some superficial gains. This issue, however, paves the way for another heated debate, i.e., model versus goal.

\section{E. Models versus Goals}

That most language learning classrooms are monolingual cannot be evaded by the justification that they are not ideal ones. Rather, it is a reality scholars and teachers cannot ignore. It could be very helpful to organize the class to have learners whose first languages are shared by all the participants even the teacher in the same classroom. This is especially important in teaching pronunciation. Non-native teachers are better able to help learners build up their pronunciation abilities and second language phonological system making use of home sound system though learners may not be able to develop native-like abilities. Therefore, the presence of a native-speaker teacher is of restricted value because the main purpose is not to develop in learners' native-like accent. This is not by any means to say that having native-speaker teachers is worthless; rather a competent non-native speaker can make a better teacher for his /her learners for they have a common language. He or she can outperform his or her native-speaker counterpart because he or she has both first and second phonological system at his/her disposal.

Accordingly, Roach (2000) meticulously makes a distinction between models and goals. His rational for doing so was that in 1970s and 1980s pronunciation teaching was commonly treated as a rather outdated activity. The justification was that teaching pronunciation was attempted to make learners sound like native speakers of Received Pronunciation which discouraged them due to difficult exercises they were required to do. This failed to give importance to communication. However, such claims in Roach's term are "misguided" because a significant growth of interest in pronunciation teaching and many new publications on the subject have been reported in recent years. Roach continues that this claim mixes up models with goals; the model chosen is Received Pronunciation but the goal is normally to develop the learners' pronunciation sufficiently to permit effective communication with native speakers. Roach, however, does not consider the role of L1 and its influence on learners' ability to improve their pronunciation especially in EFL contexts.

\section{F. The Role of Transfer}

Although the radical beliefs of the strong version of contrastive analysis (CA) have waxed and waned, many researchers reported its effects on the acquisition of a sound system. It seems that the Interlingual phonology is vulnerable to negative transfers to a great extent. Jones (2002) mentions a large number of pronunciation teaching materials including sections on contrastive analysis (Baker, 1977, Bowler \& Cunningham, 1991; Kenworthy, 1987; O'connor \&Fletcher, 1989). It has been concluded that when negative transfer from L1 is accompanied by segmented teaching of pronunciation, some persisting mispronunciations or even fossilization would be inevitable.

It should be taken into account that contrastive analysis has given way to a wider scope so that interlanguage can be explained by L1 pronunciation development. As a result, new categories for unfamiliar features are created by using existing categories where similarities exist. In light of these findings, material developers should approach predicting pronunciation problems based on learners' native language with caution (Jones, 2002). Teachers also should point out and elucidate the differences between the two phonological systems and the learners' interlanguage instead of correcting their errors.

\section{Conclusion: Why Teaching Pronunciation Seems Formidable?}

Non-native EFL teachers' incomplete mastery of the second language sound system coupled with the lack of theoretical rigor when applied to language teaching context has made teaching pronunciation a demanding task. In this respect, two views should be taken into consideration. The first one is that in spite of a lot of explicit teaching of pronunciation, learners tend to disappoint syllabus designers due to their weak performance. Thus, syllabus designers believe that teaching pronunciation should be abandoned altogether noting that pronunciation will take care of itself. According to the proponents of the second view, on the other hand, teaching pronunciation can only be a detrimental factor in the case of elementary learners. They vaguely posit that teaching phonological points to learners who are at elementary level makes learning a complex and demanding task in their eye. In order to have an optimal gain, based on the seemingly moderate view, teaching pronunciation must be postponed until later stages of development.

Furthermore, there are some other factors that influence and restrict teachers in teaching pronunciation. Chela-Flores (2001) introduces three main problems in teaching pronunciation that have a close relation to the aforementioned views; insufficient time in class, mistargeting lessons to intermediate and advanced students, and lack of awareness by students and teachers about the connection between teaching pronunciation and effective aural-oral communication. Delving into 
these areas of research can help make teachers and researchers informed so that they can come up with genuine remedies for the problems they might encounter in the classroom. This is in line with Kumaravadivelu's (2006) discussion on teacher autonomy. He believes that teachers, based on their experience and academic knowledge should come up with their own styles and strategies of teaching. This might involve the integration of different skills and components in teaching (Hinkel, 2006).

The integration of pronunciation with other skills has been argued for, but implementing such integration into language activities throughout a complete EFL/ESL program, as Chela-Flores (2001) argues, would not be possible with many course materials available. The reason is that firstly materials are designed for intermediate to advanced learners and secondly, they usually have short-term objectives. The suggested idea for settling these problems at hand is that since structures and vocabularies in pronunciation exercises are controlled, we have to deal with the immediate pronunciation needs found in the aural-oral activities of the language course used instead of first choosing a phonological feature and then finding multiple occurrences to highlight and practice it. To the possible extent, the similar structures and vocabularies used in the course should be included in pronunciation activities. If, as in learning grammar and vocabulary, learners are gradually immersed into pronunciation, their learning of pronunciation not only will not interfere with the learning of grammar and vocabulary but also it will reinforce them.

\section{REFERENCES}

[1] Acton, W. (1984). Changing fossilized pronunciation. TESOL Quarterly, 18 (1), 71-85. doi:10.2307/3586336

[2] Brown, H. D. (2007). Principles of language learning and teaching. White Plains, NY: Pearson Education.

[3] Chela-Flores, B. (2001). Pronunciation and language learning: An integrative approach. International Review of Applied Linguistics. 39, 85-101. doi:10.1515/iral.39.2.85

[4] Clariana, R. B., Wagner, D., \& Roher Murphy, L. C. (2000). Applying a connectionist description of feedback timing. Educational Technology Research and Development, 48(3), 5-21. doi:10.1007/BF02319855

[5] Ellis, R. (2003). Task-based language learning and teaching. Oxford University Press: London.

[6] Goodwin, J. (2001). Teaching Pronunciation. In Celce-Murcia (Ed). Teaching English as a second or foreign language. Boston, MA: Heinle \& Heinle.

[7] Hebert, J. (2002). PracTeSOL: It's Not What You Say, but How You Say It! In Richards, J. C. \& Renandya, W. A. Methodology in language teaching: An anthology of current practice. Cambridge: Cambridge University Press.

[8] Hinkel, E. (2006). Current perspectives on teaching the four skills. TESOL Quarterly, 40, 109-131. doi:10.2307/40264513

[9] Jones, R. H. (2002). Beyond 'Listen and Repeat': Pronunciation Teaching Materials and Theories of Second Language Acquisition. In Richards, J. C. \& Renandya, W. A. Methodology in language teaching: An anthology of current practice. Cambridge: Cambridge University Press.

[10] Krashen, S. D. (1982). Principles and practice in second language acquisition. Fairview Park: Pergamon.

[11] Kumaravadivelu, B. (2006). Understanding Language Teaching: From Method to Postmethod. Lawrence Erlbaum Associates, Mahwah: New Jersey.

[12] Lenneberg, E. H. (1967). Biological foundations of language. Hoboken, NJ: Wiley.

[13] Richards, J. C., \& Rodgers, T. S. (2001). Approaches and methods in language teaching (2nd ed.). Cambridge: Cambridge University Press.

[14] Roach, P. (2000). English phonetics and phonology: A practical course. Cambridge: Cambridge University Press.

[15] Seidlhofer, B. \& Dalton-Puffer, C. (1995). Appropriate units in pronunciation teaching: some programmatic pointers. International Journal of Applied Linguistics, 5(1), 135-146. doi:10.1111/j.1473-4192.1995.tb00076.x

[16] Widdowson, H.G., (1990). Aspects of Language Teaching. Oxford University Press: London.

Majid Soltani Moghaddam, an MA student of TEFL at the Faculty of Foreign Languages and Literatures, University of Tehran.

Morteza Nasiri, an MA student of TEFL at the Faculty of Foreign Languages and Literatures, University of Tehran.

Alireza Zarea, an MA student of TEFL at the Faculty of Foreign Languages and Literatures, University of Tehran.

Sajjad Sepehrinia, an MA student of TEFL at the Faculty of Foreign Languages and Literatures, University of Tehran. 